\title{
COVID-19 Pandemic Is Not the End of the World: A Global Perspective
}

\author{
Faisal Muhammad (iD 1, 2,* \\ ${ }^{1}$ Department of Public Health, Faculty of Allied Health Sciences, Daffodil International University, Dhaka, Bangladesh \\ ${ }^{2}$ Department of Social Work, School of Liberal Arts \& Social Sciences, University of Information Technology and Sciences, Dhaka, Bangladesh \\ "Corresponding author: Research Associate, Department of Public Health, Daffodil International University (DIU), 102 \& 102/1 Shukrabad, Mirpur Road Dhanmondi, \\ Dhaka-1207, Bangladesh. Email: fokkanya@yahoo.com \\ Received 2020 April 27; Accepted 2020 October 06.
}

Keywords: COVID-19, Epidemic, Pandemic, Global Health

\section{Dear Editor,}

This is not the first time that the world experiences epidemics and pandemics. However, going back to history, nothing has killed more people than infectious diseases (Table 1). The COVID-19 pandemic shows how vulnerable we are, and we can learn how to avoid similar pandemics in the future (1). History reveals many pandemic and epidemic diseases around the globe, including Chikungunya, Cholera, Crimean-Congo hemorrhagic fever, Ebola virus disease, Influenza, Lassa fever, Meningitis, MERS-CoV, Nipah virus infection, Plague, SARS, Smallpox, Yellow fever, and Zika virus disease, among others (2).

History reveals the worst pandemics that have killed millions of human beings around the globe. The Spanish flu was an influenza pandemic that spread around the world between 1918 and 1919. The CDC estimates that about 500 million people ( $1 / 3$ of the world's population) became infected with the virus, and about 50 million deaths occurred worldwide (3). The Black Death was one of the most devastating pandemics in human history between 1347 and 1351 that killed an estimated 75 to 200 million people across Europe and Asia. The Black Death re-surfaced in London in 1665 for the Great Plague of London and killed 20.0\% of London's population in just 1.5 years, with an estimated 100,000 deaths (3). The "Asian Flu" began in East Asia in 1957. The influenza virus of the H2N2 strain was first discovered in Singapore and killed about 1.1 million people worldwide (3). The Hong Kong flu pandemic of 1968 originated in China. Caused by an influenza virus (H3N2), it was the third pandemic flu outbreak to occur in the 20th century and killed at least one million people globally. The "swine flu" occurred in 2009 with a novel influenza virus, H1N1. The virus was first detected in the US and spread quickly to the US and the world. Between 2009 and 2010, there were 60.8 million cases and at least 575,400 deaths worldwide. HIV/AIDS was first discovered in the early 1980s. AIDS was first detected in American gay communities and has killed about 32 million people worldwide since it was discovered (3).

In this modern era, the outbreaks (Pandemic, Sporadic, or Epidemic) are almost constant; however, not every outbreak reaches the pandemic level, as is in the case of COVID19. It is normal to have the outbreak of infectious diseases everywhere as human beings have spread across the globe. Nowadays, it is easy to move from one part of the world to another within a short period, and this can help (directly or indirectly) in the easier transmission of infectious diseases across the world. Nevertheless, healthcare progress has helped in achieving possible measures to prevent, tackle, or give a quick response to an outbreak in any part of the world.

\section{Footnotes}

Authors' Contribution: All the work has been done by Faisal Muhammad.

Conflict of Interests: The author has no conflict of interest.

Ethical Approval: The study was approved by the FAHS Research Ethics Committee in the Department of Public Health, Daffodil International University, Dhaka, Bangladesh.

Funding/Support: None declared. 


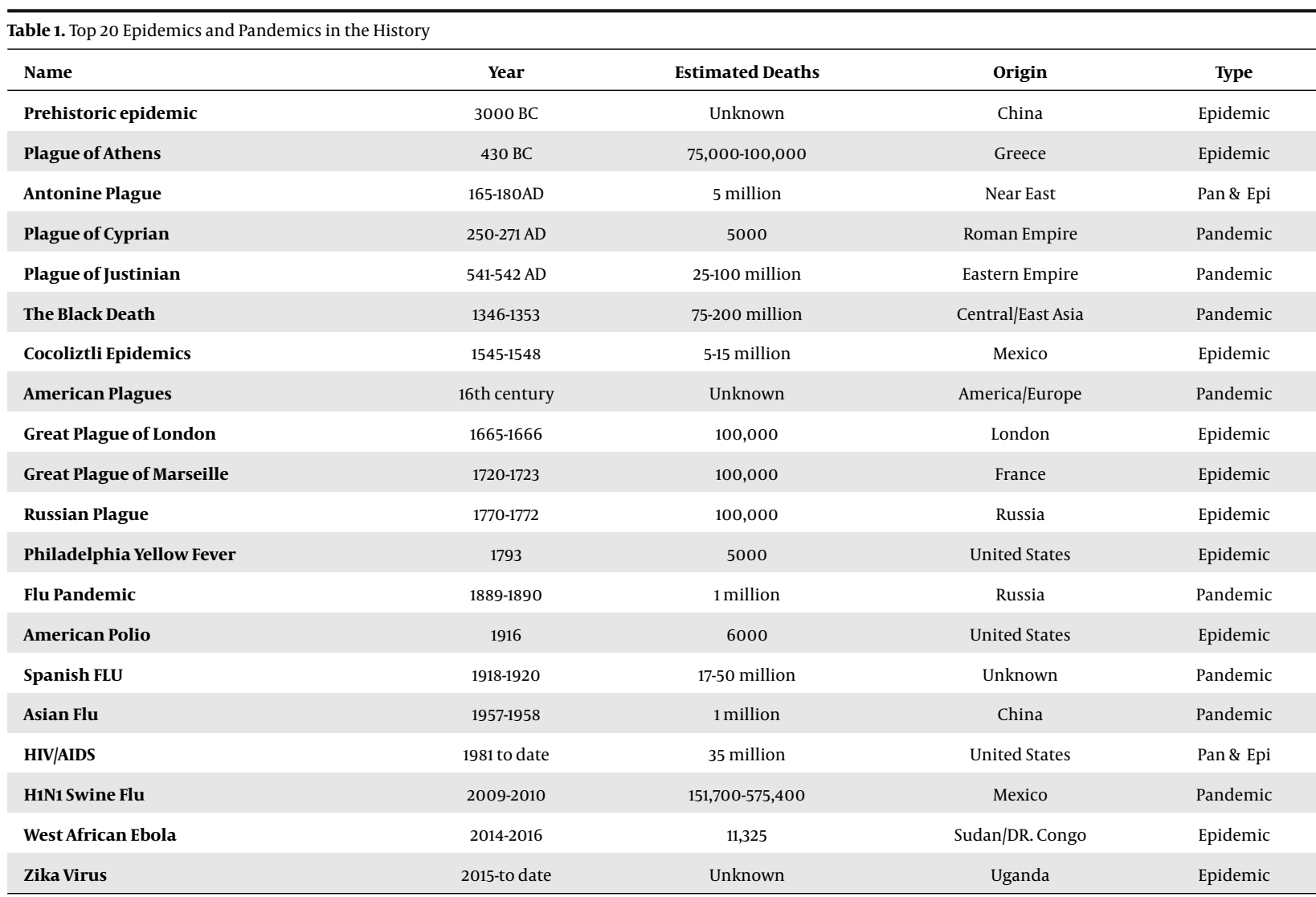

\section{References}

1. Walsh B. Covid-19: The history of pandemics. 2020, [cited April 15,]. Available from: https://www.bbc.com/future/article/20200325-covid19-the-history-of-pandemics.
2. WHO. Disease Outbreaks. 2020, [cited April 15]. Available from: https: //www.who.int/emergencies/diseases/en/

3. Miguel K. Here's a look at some of history's worst pandemics that have killed millions. 2020, [cited February 28]. Available from: https://abc7news.com/pandemic-epidemic-coronavirus-definitionwhat-is/5974174/. 